\title{
ABBREVIATIONS
}

$A B$

ARF

$A S O B$

Astronomer

BAV

BHL

$\mathrm{BnF}$

CCCM

$\mathrm{CCM}$

CCSL

CSEL

EA

EME

In Mattheum

LCL

Mabillon
Annales Bertiniani, ed. R. Rau, Quellen zur karolingische Reichsgeschichte 2 (Darmstadt, 1972), pp. 13-287.

Annales regni Francorum, ed. F. Kurze, MGH SRG 6 (Hanover, 1895).

Acta Sanctorum Ordinis Sancti Benedicti, ed. J. Mabillon, 9 vols. (Paris, 1668-1701).

Astronomus, Vita Hludowici imperatoris, ed. E. Tremp, MGH SRG 64 (Hanover, 1995).

Biblioteca Apostolica Vaticana

Bibliotheca Hagiographica Latina

Bibliothèque Nationale de France

Corpus Christianorum, Continuatio Mediaevalis

Corpus consuetudium monasticarum

Corpus Christianorum, Series Latina

Corpus Scriptorum Ecclesiasticorum Latinorum

Paschasius Radbertus, Epitaphium Arsenii, ed. E. Dümmler, in Abhandlungen der Königlichen Akademie der Wissenschaften zu Berlin, Phil.-Historische Abhandlungen 2 (Berlin, 1900), pp. 1-98.

\section{Early Medieval Europe}

Paschasius Radbertus, Expositio in Matheo libri XII, ed. B. Paulus, 3 vols., CCCM 56-56A-56B (Turnhout, 1984).

Loeb Classical Library

Epitaphium Arsenii seu Vita venerabilis Walae abbatis Corbeiensis in Gallia, ed. J. Mabillon, ASOB, vol. IV (Paris, 1677), pp. 453-522. 


\section{ABBREVIATIONS}

$M G H$

Capit.

Conc.

$D D L d F$

DD Merov.

$E p p$.

Poet. lat.

$S R G$

$S R M$

$S S$

Niermeyer,

Lexicon

Minus

Nithard

$P L$

prol.

$R B$

Regesta imperii

Relatio episcoporum (833)

$\mathrm{SC}$
Monumenta Germaniae Historica

Capitularia regum Francorum

Concilia Karolini Aevi

Die Urkunden Ludwig des Frommen, 3 vols., ed. T. Kölzer et al., MGH Diplomata Karolinorum II, 1-3 (Wiesbaden, 2016).

Die Urkunden der Merowinger, 2 vols., ed. T. Kölzer, MGH Diplomata regum Francorum e stirpe Merovingica (Hanover, 2001).

Epistolae Karolini aevi

Poetae Latini aevi Carolini

Scriptores rerum Germanicarum

Scriptores rerum Merovingicarum

Scriptores

J. F. Niermeyer, with C. van de Kieft, Mediae Latinitatis Lexikon Minus (Leiden/New York/Cologne, 1993).

Nithard, Historiarum libri $I V$, ed. and trans. P. Lauer, revised by S. Glansdorff, Nithard: Histoire des fils de Louis le Pieux (Paris, 2012).

Patrologiae cursus completus, series latina, ed. J.-P. Migne, 221 vols., Paris (1841-64).

prologue

Regula Benedicti, ed. and trans. B. L. Venarde, The Rule of Saint Benedict. Dumbarton Oaks Medieval Library 6 (Cambridge, MA, 2011).

J. F. Böhmer and E. Mühlbacher, Regesta Imperii, vol. I: Die Regesten des Kaiserreichs unter den Karolingern, 751-918, 2nd edn (Innsbruck, 1908); http://www.regesta-imperii.de

Episcoporum de poenitentia, quam Hludowicus imperator professus est, relatio Compendiensis, MGH Capit. II/2, pp. 51-5.

Sources Chrétiennes 


\section{ABBREVIATIONS}

Settimane Settimane di studio del centro italiano di studi sull'alto medioevo.

Thegan Thegan, Gesta Hludowici imperatoris, ed. E. Tremp, MGH SRG 64. (Hanover, 1995).

$V A$

Paschasius Radbertus, Vita Adalhardi, PL 120, cols. 1507-82; trans. Cabaniss, Charlemagne's Cousins: Contemporary Lives of Adalhard and Wala (Syracuse, NY, 1967) pp. 25-82. 